\title{
LA CASI DESCONOCIDA EXPEDICIÓN DEL COMODORO ROQUE GURUCETA AL PACÍFICO
}

\author{
Ernesto Piero Bazzetti De los Santos \\ Universidad Ricardo Palma \\ pbazzetti13@hotmail.com
}

\section{RESUMEN}

La Expedición auxiliar de Roque Guruceta al Pacífico fue el último y más importante refuerzo naval que se hizo presente en el Pacífico, con el objetivo de ayudar a las fuerzas realistas que aún mantenían el control del Perú y el Alto Perú.

\section{PALABRAS CLAVE}

Independencia / Navío/ Bergantín/ Comodoro

\begin{abstract}
\section{KEYWORDS}

Independence/ Ship/ Brig/ Commodore
\end{abstract}

Roque Guruceta's Pacific Expedition was the last and most important naval reinforcement that was present in the south Pacific, with the objective of helping the realistic forces that still had control of Peru and Upper Peru. 
En junio de 1823 el general español José de Canterac se apoderó de Lima al frente de sus tropas, y permaneció durante un mes en la ciudad, en el Callao quedaron 2,000 soldados patriotas. No obstante, las malas condiciones en que se hallaba esta guarnición no experimentaron mejoría alguna, y hubo varias instigaciones sediciosas hacia las tropas del Callao para pasarlas al bando realista. Como resultado de ello estallaría, como veremos más adelante la llamada Sublevación del Callao.

En el Callao surgió la discordia entre el Congreso y Riva Agüero, discordia que estaba latente desde que se produjo el Motín de Balconcillo. Amparado por Sucre, el Congreso despojó a Riva Agüero de sus atribuciones de Presidente de la República y se las otorgó al general venezolano, motivando con ello la primera anarquía en el Perú republicano, conducta que merece dura censura, porque no se debe fomentar la división entre los peruanos cuando la Patria se encuentra en peligro.

Riva Agüero despojado del mando y con orden de ser deportado (por los decretos dados en el Callao el 19, 22 y 23 de junio), se embarcó en el puerto rumbo a Trujillo con sus Ministros y parte de los diputados, estableciendo en dicha ciudad su gobierno. Poco después Riva Agüero disolvió el Congreso y creó un Senado de 10 miembros.

Al desocupar los realistas la capital el 16 de julio, volvieron a Lima los que se habían trasladado al Callao. Sucre encargó el gobierno a José Bernardo de Tagle y Portocarrero IV Marqués de Torre Tagle, más conocido como Torre Tagle; mientras él se dirigía al sur al mando del ejército en apoyo de la expedición de Santa Cruz que trata de terminar con el Ejército Real del Perú siendo posteriormente derrotada. Torre Tagle reunió en Lima a los diputados que no habían ido a Trujillo y restableció el funcionamiento del Congreso (6 de agosto). El Congreso eligió a Torre Tagle Presidente de la República. Así, en agosto de 1823, el Perú estaba dividido con dos Presidentes y dos Congresos, uno en Lima y otro en Trujillo. En esos momentos venía al Perú, como salvador de la situación, el Libertador Don Simón Bolívar.

El $1^{\circ}$ de septiembre de 1823 llegó al Callao a bordo del bergantín Chimborazo Don Simón Bolívar. Los castillos anunciaron con salvas de artillería la presencia del Libertador en el puerto. Ese mismo día desembarcó siendo recibido por el Presidente Torre Tagle y los principales funcionarios. En Lima el ejército formo en las calles y en las casas de la ciudad se izaron las banderas del Perú, Chile, Colombia y Argentina, siendo recibido entusiastamente y conducido en medio de grandes aclamaciones a la casa que se le tenía preparada en la calle San José. 
Bolívar venía reconociendo como gobierno legítimo del Perú al de Torre Tagle y al Congreso en Lima. Sin perder tiempo decretó este Congreso, el 10 de septiembre, que el Libertador asumía la suprema autoridad militar en toda la República. Seguía siendo el Marqués de Torre Tagle Presidente, pero debiendo ponerse en todo de acuerdo con el Libertador.

El único obstáculo que tenía Bolívar en el Perú para asumir el poder era Riva Agüero y sus partidarios que dominaban toda la región del Trujillo y Huaráz, con una fuerza de más de 3,000 hombres. Autorizado por el Congreso, Bolívar entró en conferencias con Riva Agüero que se realizaron en Huaráz primero y en Pativilca después, entre delegados de ambos caudillos, sin llegar a ponerse de acuerdo.

Mientras se desarrollaban las conferencias entre Bolívar y Riva Agüero, se realizaban al mismo tiempo, en forma secreta, negociaciones entre Riva Agüero y el Virrey La Serna para pactar un armisticio. Por estas negociaciones Riva Agüero ha sido acusado de traición, pero no hay tal, porque Riva Agüero entró en negociaciones con el Virrey como anteriormente lo había hecho San Martín y como después lo haría el mismo Bolívar, sin renunciar a la independencia del Perú.

En esta situación, Bolívar decidió a mediados de noviembre abrir campaña contra Riva Agüero, dirigiéndose al norte. La guerra civil estaba próxima a estallar. Felizmente no ocurrió así porque en la madrugada del 25 de noviembre el coronel Don Antonio Gutiérrez de la Fuente tomo prisionero a Riva Agüero en Trujillo, junto con sus principales partidarios y desoyendo las órdenes impartidas para que lo fusilara, lo dejó embarcarse para Guayaquil y de ahí a Europa, con lo que terminó esta lamentable crisis política en el Perú.

De regreso de la campaña contra Riva Agüero, Bolívar se vio obligado en los primeros días de enero de 1824 a detenerse en Pativilca, muy enfermo. Con la salud quebrantada, pero con el gran espíritu que siempre mostró ante la adversidad, Bolívar estableció su Cuartel General en Pativilca y se dedicó a preparar la campaña contra los españoles. Para ganar tiempo, insinuó a Torre Tagle la necesidad de entrar en negociaciones con los realistas para pactar un armisticio. El Congreso aprobó estas negociaciones y fue enviado al campamento de Canterac, en Jauja, el Ministro de Guerra general José Félix de Berindoaga, pero el general español no aceptó las negociaciones.

Ocurrió entonces que Torre Tagle estaba desde hacía algún tiempo en negociaciones secretas con los españoles para terminar la guerra sobre la base de que 
Bolívar saliera del Perú. Cuando Berindoaga fue a Jauja, su ayudante fue portador secreto, sin que el Ministro lo supiera, de nuevas comunicaciones que Torre Tagle enviaba a Canterac. Al ser poco después descubiertas estas negociaciones, Bolívar culpó de ellas tanto a Torre Tagle como a Berindoaga, siendo fusilado Berindoaga.

A principios de febrero de 1824 la crítica situación por la que atravesaba el país se complicó aún más cuando el 5 de febrero ocurrió la sublevación de una parte de las tropas en las fortalezas del Real Felipe en el Callao, y como resultado de ella los españoles se apoderaron de ese importante lugar al solicitar los sublevados la protección de los jefes realistas que se encontraban presos. Estos comunicaron la noticia al general Canterac, quien envió a los generales Juan Antonio Monet y José Ramón Rodil con grandes refuerzos, pasando así la mejor plaza fuerte en el Pacífico a poder de España. Ante la gravedad de la situación Bolívar ordenó evacuar la Capital, replegar las tropas hacia Pativilca, y sacar de Lima todo lo que pudiera ser útil, aún por la fuerza, porque como diría Bolívar:

\section{la guerra no se hace por el amor de Dios.}

En esta delicada situación, el Congreso dio el 10 de febrero de 1824 un trascendental decreto entregando a Bolívar la plenitud de los poderes de Estado para que hiciera frente a la situación, declaró en suspenso la autoridad de Torre Tagle, la vigencia de la Constitución de 1823 y luego se declaró en receso. Torre Tagle descubierto en sus negociaciones con los españoles se refugió en el Callao en donde falleció poco después. Bolívar era Dictador del Perú.

Entre estos acontecimientos, se prepara en España la flotilla de buques de guerra auxiliar, compuesta por el navío Asia, al mando del Capitán de Navío Roque Guruceta, jefe de la expedición, que actuaba de Comodoro, y el bergantín Aquiles al mando del Teniente de Navío don José Fermín Pavía.

El 13 de enero de 1824 zarpa de Cádiz los buques con 1,000 hombres entre tripulaciones y soldados. Después de un largo viaje, el 15 de marzo la flotilla recala en Puerto Egmont, en las Islas Malvinas, para un breve descanso y preparar los aparejos para cruzar el Cabo de Hornos.

El Asia, fue un navío de línea español, botado en 1791 en el Arsenal de La Habana fue incorporado en ese mismo año. Eslora: 50.42 metros. Manga: 13.79 metros. Puntal: 6.66 metros. Calado: 6.53 metros. Armamento: 74 cañones; 26 cañones de 24 libras, 28 cañones de 18 libras, 14 cañones de 8 libras, 4 obuses de 30 
libras, 2 obuses de 24 libras, y 4 obuses de 4 libras. Propulsión: vela. Tripulación: 542 hombres.

El Aquiles, fue un bergantín español. Armamento: 20 cañones de 12 libras.

Marino español, Cádiz 1771-Madrid 1854; hijo de un mercader guipuzcoano afincado en la capital andaluza. Se alistó desde muy joven en la marina participando a las órdenes de los generales Lángara, Córdoba, Mazarredo y Álava en múltiples acciones de guerra y ascendiendo a los puestos más elevados de la jerarquía militar. Hallándose como comandante general del Apostadero del Ferrol, desbarató en 1832 la conspiración que se estaba fraguando allí en favor del infante Don Carlos.

Marino español, Arsenal de la Carraca 1774-Madrid 1850; hijo de un oficial de contaduría de la armada. Se alistó desde muy joven en la marina participando en múltiples acciones de guerra.

El 27 de marzo zarpa de aquel lugar con dirección al puerto de San Carlos de Ancud en Chiloé donde llegan el 27 de abril. El gobernador de la isla, Antonio de Quintanilla ${ }^{5}$ le facilita todas las provisiones necesarias a la flotilla de Guruceta.

Por aquel entonces el Callao había sido retomado por los realistas, encontrándose la Fortaleza del Real Felipe al mando del brigadier José Ramón Rodil y Campillo. Siguiendo su propio plan, en el Callao, el brigadier Rodil en junio de 1824, falto de personal con experiencia marinera, ordenó embarcar a todos los prisioneros patriotas que tuvieran experiencia y conocimientos en navegación y marinería de entre los que estaban confinados en la prisión de la fortaleza. Así fue, como el capitán chileno Pedro Angulo de Novoa fue embarcado inicialmente en el bergantín Constante, a servir a la fuerza como oficial, junto a marineros chilenos y de otras nacionalidades.

Después de invernar en Chiloé, abasteciéndose de los escasos medios de que disponía el brigadier Quintanilla, Guruceta se decidió a zarpar al Perú, levó anclas el 15 de agosto. Para no tener interferencias en su travesía, trazó un rumbo a 300 millas de la costa y, en esta forma, evadir toda posible interceptación de las unidades chilenas; sin embargo, por una mala coincidencia fue avistado por el pesquero inglés SNIPE, procedente de Calcuta, que al fondear en Valparaíso el 26 de agosto, dio aviso a las autoridades chilenas de la presencia de la flotilla en el Pacífico. 
La flotilla arribó primero a Quilca en Arequipa para recabar información del panorama del momento, cerciorándose de la ausencia de elementos adversarios en el mar y continuar luego a su destino al Callao, donde arribó el 13 de septiembre para fondear al abrigo de las fortificaciones terrestres.

El comandante Guruceta desperdició la oportunidad de batir a los buques peruanos que bloqueaban el puerto dejándolos ir, pese al desafío a que le instó el almirante Martin Jorge Guise, que habiendo levado anclas desde su posición en la isla San Lorenzo, intentó retarlo disparando sendas salvas de artillería.

Los buques peruanos que estaban compuestos por la fragata insignia, protector, ex prueba; una corbeta y cuatro bergantines dieron a su vez la vela y aceptaron el combate.

Al cabo de un corto tiempo, los buques peruanos se pronunciaron en retirada tras haber recibido el buque insignia Protector, varios impactos en casco y aparejo. El jefe español continuó la caza por dos horas más, volviendo luego a puerto, pareciéndole, según sus propias palabras:

indecoroso ocuparse de aquellos barcuchos fugitivos.

Antonio de Quintanilla y Santiago (Pámanes, Cantabria, España;1787Almería, Andalucía, España; 1863) fue un militar español que pasó en su juventud a la gobernación de Chile y después de dedicarse al comercio en la provincia de Concepción, ingresó en el ejército real en 1813. Llegó a ocupar el puesto de gobernador de Chiloé hasta la conquista de ese territorio por tropas chilenas en enero de 1826. Luego del fin de la guerra, regresó a España con su familia, y vivió allí hasta su muerte.

Esta extraña reacción de un jefe, en la única oportunidad que se le presentó para destruir la escuadra enemiga y asegurar el dominio del mar, bajó la moral de su gente que apreciaba la inutilidad de su presencia en el Pacífico, esto afectaría hondamente en los próximos acontecimientos. Aunque logró levantar temporalmente el asedio marítimo del Callao, tras reaprovisionarse y reforzar sus guarniciones con 200 soldados del Batallón Arequipa al mando del brigadier Mateo Ramírez zarpó al sur.

El comodoro Guruceta recibió el título de Comandante en Jefe de las Fuerzas Navales Españolas en el Pacífico, Ahora además de contar con el navío 
Asia y el bergantín Aquiles se le unieron a sus fuerzas la corbeta Victoria de Ica y los bergantines Constante y Pezuela, estos buques fueron recapturados al recuperarse el Callao. Con estos buques concentrados en el Callao y con un extenso litoral que controlar desde California hasta el cabo de Hornos, tenían posibilidades de operar, desde Quilca, al sur del Perú, y en Chiloé, en Chile austral.

El 20 de octubre, el comodoro Guruceta zarpa del Callao con su escuadra escoltando a dos transportes con tropas con destino a Chiloé, Ilo y Quilca, donde entró el 19 de noviembre. Zarpó de Quilca el 4 de diciembre y fondeo en Ilo, zarpando el día 14 para encontrar por espacio de 4 días a la escuadra al mando de Manuel Blanco Encalada, regresando a Quilca el 19 de diciembre. El 1 de enero de 1825 Guruceta sale de Quilca para regresar al Callao.

$\mathrm{Al}$ enterarse Roque Guruceta en Quilca de la derrota de los realistas en la batalla de Ayacucho y de la capitulación donde se incluía la rendición de las fuerzas marítimas. Guruceta se desentendió del acuerdo y decidió abandonar la costa peruana.

Guruceta zarparía sin esperar al virrey La Serna ni tomar contacto con el puerto del Callao para, en palabras del brigadier Andrés García Camba, ofrecer sus importantes servicios al sitiado Rodil. Para economizar sus raciones ordenó además desembarcar a los veteranos del Batallón de Arequipa a los que abandonó a su suerte.

El 2 de enero de 1825 zarpó el navío Asia del puerto de Quilca con rumbo a las Filipinas junto a los bergantines Constante y Aquiles y la corbeta transporte Clarington. El resto de las fuerzas marítimas salieron para Europa; la corbeta Victoria de Ica y el bergantín Pezuela, y para Chiloé la balandra Real Felipe y el transporte Trinidad.

Con Guruceta iban a bordo dos antiguos oficiales del Ejército Real del Perú, los brigadieres Ramírez y García Camba, este último dejaría en sus memorias una detallada descripción de los acontecimientos posteriores. Después de salir de las costas americanas. Guruceta fondearía en las islas Marianas para reparaciones y aprovisionamiento en marzo de 1825.

Mateo Ramírez, España, ¿?-Sevilla, 1847, militar español, oficial del Ejército Real del Perú, durante la guerra de independencia hispanoamericana y Mariscal de Campo durante la Primera Guerra Carlista. 
Andrés García Camba, Lugo, 1793-Madrid, 1861 fue un militar, político y escritor, natural de Galicia. Las memorias que escribió sobre su actuación en la guerra de la independencia del Perú ha sido una fuente muy recurrida por los historiadores.

Al llegar a la isla Guaján el día 10 de marzo, la tripulación del Asia, se sublevó, mientras que la del bergantín Constante lo hizo el 12 de marzo y abandonó a la oficialidad en tierra y pusieron de nuevo rumbo a América llegando posteriormente a México donde las naves serían entregadas a esas autoridades. El 28 de abril los amotinados avistaron el puerto de la bahía de Monterrey, en la Alta California, entrando a la bahía con bandera de parlamento. Las autoridades de Monterrey aceptaron los términos que proponían los amotinados: recibir sueldos atrasados, jurar fidelidad a México y obtener para los que no quisieran permanecer en México, facilidades para partir a donde desearan. De Monterrey zarparon rumbo a Acapulco, portando como estandarte una bandera con los colores azul, blanco, y rojo y una explicación de no haber encontrado lanilla verde, quedó bajo el mando de capitán José María Tosta.

El 17 de junio de 1825 arriba en Acapulco y allí es renombrado Congreso Mexicano convirtiéndose en el mayor y más potente buque de la recién constituida Armada de México. A partir de ese año realizaría varios viajes, en los que hubo problemas de indisciplina.

Después de retirarlo del servicio activo por las malas condiciones en las que se encontraba en 1827 se utilizó al navío como buque cuartel, como pontón y finalmente como prisión. En 1832, debido a que hacía agua, fue remolcado hasta el este del bajío de Ulúa, donde terminó hundiéndose lentamente.

Los oficiales entre ellos Guruceta abandonados fueron recogidos días después por un ballenero inglés en el que fueron transportados a Manila. Desde ese lugar se envió el navío Soberano en busca del buque amotinado, aunque no tuvo éxito en la tarea de ubicarlo.

En cuanto al bergantín Aquiles, se mantuvo fiel algunos días más, pero el 14 de marzo el marino chileno Pedro Angulo Novoa que estaba a bordo en calidad de prisionero logró sublevar el buque con el que se dirigió a México a Santa Bárbara, Alta California, donde recalaron el 29 de abril enarbolando la bandera chilena. Como el gobernador de esa región quisiera apoderarse del buque, Pedro Angulo zarpó precipitadamente desde este puerto el 6 de mayo llegando a Valparaíso el 23 
de junio, donde hizo entrega de la nave al gobierno chileno. En la Guerra contra la Confederación Perú-boliviana capturó la barca Santa Cruz, el bergantín Arequipeño y la goleta Peruviana. Se perdió en Valparaíso el 24 de julio de 1839 en un fuerte temporal.

La escuadra de Guruceta se había retirado de las costas americanas, dejando los mares totalmente a disposición de los patriotas, demostrando que la expedición había sido un fracaso y la total ineptitud de su comandante, al dejarse llevar por el pánico tras la derrota de Ayacucho, lo que le valió ácidos comentarios de sus connacionales. De España ya no llegaría ninguna otra expedición para auxiliar a las fuerzas españolas en el Pacífico. Pedro Angulo Novoa, Concepción 1799 Valparaíso 1859, oficial de la marina de Chile.

Ahora el puerto del Callao y la austral isla de Chiloé, aún bajo dominio realista y negándose a aceptar la capitulación de Ayacucho, quedaban a merced de los patriotas. El brigadier Rodil se lamentó del incomprensible abandono en que le había dejado la armada española diciendo:

Me he persuadido de que la escuadra que Don Roque Guruceta tiene a sus ordenes se ha hecho a la vela desde Quilca para Manila. Esto permite inferir que el honor, la constancia y la fortuna han desamparado a nuestros compañeros de armas en estas regiones.

Dos días después, y para la mala fortuna de los sitiados españoles en el Callao, se presenta ante el puerto una imponente flota combinada de los patriotas al mando del almirante Manuel Blanco Encalada con la fragatas O'Higgins y Protector, la corbeta Pichincha y los bergantines Limeña, Moctezuma, Congreso, Macedonia y Chimborazo, estableciéndose un bloqueo naval complementario al terrestre que ya se sufría por la guarnición española.

Por otro lado, el gobierno chileno, encabezado por el general Ramón Freire, comandaba una segunda expedición en 1826 para derrotar a las tropas españolas que resistían en Chiloé, derrotándolas y obligándolas a capitular el 15 de enero de 1826, firmándose el Tratado de Tantauco, acuerdo que marcó la incorporación definitiva del archipiélago a Chile. Una semana después de este hecho, se produjo la rendición de las fuerzas españolas en el Callao, el último reducto español en América del Sur. 


\section{REFERENCIAS BIBLIOGRÁFICAS}

Milla B. (1998). Compendio Histórico del Perú, España: Editorial Milla Batres.

Tauro Del Pino, A. (2001). Enciclopedia Ilustrada del Perú, Lima: Editorial PEISA.

Urrutia, E. Galería Biográfica De Vascos Ilustres. Roque Guruzeta, España: Euskalerriaren Alde.

Valdizán Gamio, J., (1984). Historia Naval del Perú, Dirección General de Intereses Marítimos, Perú.

Varcarcel, D. y Docafe, E., (1973). Historia General de los peruanos: El Perú Republicano, Lima: Editorial PEISA. 